\title{
Maximization of Daily Canopy Photosynthesis: Effects of Herbivory on Optimal Nitrogen Distribution
}

\author{
Brian A. STOCKHOFF ${ }^{\dagger}$ \\ Department of Biology, University of Michigan, Ann Arbor, MI 48109-1048 U.S.A.
}

(Received on 19 September 1991, Accepted on 25 March 1994)

\begin{abstract}
Recent models have shown that higher leaf nitrogen concentration per unit area maximizes nitrogen use efficiency with increasing light intensity. As a result, total canopy photosynthesis is maximized when nitrogen concentrations are higher towards the top of a canopy. Expanding upon this previous work, a model of daily canopy photosynthesis was constructed based on distributions of light, leaf nitrogen, and folivory. The model indicates that the optimal distribution of nitrogen depends significantly upon both the severity and location of folivory. Relative to nitrogen distributions that maximized daily canopy photosynthesis without herbivory, the optimal nitrogen distribution shifted towards either more uniform or skewed distributions when herbivores fed on high nitrogen foliage at the top of the canopy or on low nitrogen foliage towards the bottom of the canopy, respectively.

These results suggest that, because foliar losses are balanced by increased irradiance of remaining leaves, plants' nitrogen allocation patterns should depend on how severe defoliation is and whether damage is concentrated towards the top or bottom of a canopy. Moreover, the critical importance of nitrogen distribution to photosynthesis implies that plants should not necessarily minimize loss of leaf area to folivores, but should protect the ratio of total nitrogen to leaf area and the distribution of nitrogen within the canopy. As a corollary to the nutrient stress hypothesis of plant defense theory, the model suggests that plants may need to translocate nutrients to maintain an optimal distribution in the canopy following herbivory. The model reinforces the point that leaf area loss alone is a poor indicator of loss of photosynthetic capacity when nitrogen is non-uniformly distributed among leaves. To accurately assess damage to a plant, one must consider not only what resources have been removed, but what resources remain.
\end{abstract}

\section{Introduction}

Maximization of photosynthesis by a plant is likely to occur with a non-uniform distribution of nitrogen within the canopy. This is because at high light levels, such as those at the top of a canopy, light is unlikely to be limiting and photosynthetic capacity will be strongly correlated with leaf nitrogen content (Mooney et al., 1981; Field \& Mooney, 1986). On the other hand, at low light levels, such as those at the bottom of a canopy, increasing leaf nitrogen would yield only small photosynthetic gains because photon interception is limiting (Björkman, 1981) and

$\dagger$ Present address: Mycogen Corporation, 4980 Carroll Canyon Road, San Diego, CA 92121, U.S.A. because maintenance requirements and carbon losses during darkness are relatively greater (Gulmon \& Chu, 1981). Thus, total canopy photosynthesis is maximized when nitrogen concentrations are higher towards the top of a canopy (Field, 1983).

In a model of daily canopy photosynthesis, Hirose \& Werger (1987b) demonstrated that the specific distribution of nitrogen that maximizes daily canopy photosynthesis varies according to canopy density and the nitrogen pool available for allocation among leaves. The optimal concentration of nitrogen in leaves in the uppermost part of the canopy was found to increase with increasing canopy density and total canopy nitrogen. Because the model assumes that total canopy nitrogen and canopy density are fixed within a plant, the effects of changes in nitrogen and 
canopy density on photosynthesis were compared only between plants having different canopy densities and nitrogen allocation patterns.

A single plant, however, may experience changes in total nitrogen and leaf area as a consequence of herbivory. Leaf removal will decrease the total nitrogen and leaf area within a canopy, but simultaneously will increase the amount of light penetrating to lower levels. Photosynthesis subsequently will be reduced by nitrogen losses, and increased by greater light availability to remaining leaves. The precise balance of costs and benefits of leaf removal to daily canopy photosynthesis will depend on the nitrogen distribution within the canopy and the position of foliage that is lost to herbivory. As a result, the nitrogen distribution which maximizes canopy photosynthesis prior to herbivory does not necessarily maximize photosynthesis after herbivory, and the optimal distribution of nitrogen among leaves within a canopy likely will depend on the severity and location of photosynthetic tissue losses, and the degree to which a plant can compensate for lost photosynthetic tissue.

Here, a model is presented that examines the distribution of nitrogen that maximizes canopy photosynthesis in the presence of herbivores. This model expands upon that of Hirose \& Werger $(1987 b)$, but is novel in that it includes effects of herbivory. Several feeding rules for herbivores are formulated and the optimal nitrogen allocation pattern, i.e. the nitrogen distribution that maximizes canopy photosynthesis, is determined. The model predicts that optimal nitrogen distribution in a canopy will depend upon the position of foliage removed within the canopy and on the intensity of herbivory.

\section{The Model}

The model begins by assuming a plant that has some pre-existing distribution of nitrogen within its canopy (specified by $K_{\mathrm{a}}$; see below), and that generalized herbivores remove horizontal layers of foliage from the top, middle, or bottom of the canopy. The amount of foliage removed depends on whether the herbivore's foraging "goal" is to consume a fixed amount of nitrogen, or to consume a fixed leaf area or leaf mass. The rules governing foliage removal are not intended to mimic any particular type of herbivore but are intended to test the effects of a broad range of leaf removal patterns. The overall level of photosynthesis will be diminished by herbivory because leaf nitrogen is removed, but will be increased in remaining foliage below regions of leaf removal because of greater light penetration. The suppression of photosynthesis will not be identical for all nitrogen distributions because different nitrogen distributions will result in removal of different leaf areas or different amounts of nitrogen. In this model, the daily canopy photosynthesis of the new canopy after attack is compared with that of a plant which suffered attack by identical herbivores, but which had a different initial nitrogen distribution.

The model consists of four parts. The first part determines nitrogen concentration of leaves at different levels in the canopy. The second part determines how herbivory affects the nitrogen distribution and light penetration through the canopy. The third part calculates irradiance of leaves at different canopy depths. The fourth part calculates net photosynthesis (carbon exchange rate) per unit leaf area as a function of irradiance, nitrogen concentration, and dark respiration. Integration of net photosynthesis over all depths for a 24 -hr period yields daily net photosynthesis in the canopy. Parts 1, 3, and 4 are adapted directly from Hirose \& Werger (1987b); part 2 is novel. Symbol definitions are provided in Appendix A.

\subsection{NITROGEN DISTRIBUTION AMONG LEAVES WITHIN A CANOPY}

The leaf nitrogen content per unit area, $N_{\mathrm{L}}$, at a particular leaf area index (depth from the top of the canopy) $F$ within the canopy is given by

$$
N_{L}=N_{0} \exp \left(-K_{\mathrm{a}} F / F_{t}\right) .
$$

Total leaf nitrogen per unit ground area $\left(N_{\mathrm{t}}\right)$ is given by the integral of leaf nitrogen over all depths in the canopy:

$$
N_{\mathrm{t}}=\int_{0}^{F_{\mathrm{t}}} N_{\mathrm{L}} \mathrm{d} F=N_{0} F_{\mathrm{t}}\left(1-\mathrm{e}^{-K_{\mathrm{u}}}\right) / K_{\mathrm{a}},
$$

where $N_{0}$ is the leaf nitrogen content per unit area at the top layer of the canopy, and $F_{\mathrm{t}}$ is the total leaf area index (leaf area per unit ground area). $K_{\mathrm{a}}$ is the coefficient of leaf nitrogen allocation, and determines how $N_{\mathrm{t}}$ is apportioned throughout $F_{\mathrm{t}}$. The canopy has a uniform distribution of nitrogen when $K_{\mathrm{a}}=0$, so that every leaf has a nitrogen concentration equal to the mean. As $K_{\mathrm{a}}$ increases $\left(K_{\mathrm{a}}>0\right)$, the nitrogen distribution becomes skewed so that leaves at the top of the canopy have higher concentrations than lower leaves.

$N_{0}$ is defined as

$$
\begin{array}{ll}
N_{0}=K_{\mathrm{a}} N_{\mathrm{1}} / F_{1} /\left(1-\mathrm{e}^{-K_{\mathrm{a}}}\right) & K_{\mathrm{a}} \neq 0 \\
N_{0}=N_{\mathrm{t}} / F_{1} & K_{\mathrm{a}}=0 .
\end{array}
$$




\subsection{HERBIVORE FEEDING RULES}

Either no leaves were removed, or herbivores removed foliage in accordance with one of two feeding criteria:

Nitrogen removal. Herbivores consume foliage until some nitrogen requirement $\left(N_{\mathrm{R}}\right)$ is met. Nitrogen is limiting to the growth of many herbivores, insects in particular (White, 1978; Mattson, 1980; Scriber, 1984), and hence can be important in determining food choice. To approximate the severity of leaf removal typically found in nature, this requirement leads to removal of $0-20 \%$ of the total canopy nitrogen $\left(N_{\mathrm{t}}\right)$. On average, herbivores consume about $2.5 \%$ of the net production of temperate deciduous forests and $12 \%$ of that in old field habitats (Wiegert \& Owen, 1971).

Leaf area removal. Herbivores remove foliage until a leaf area requirement $\left(L_{R}\right)$ is satisfied. Leaf area removal may be translated into consumption of a particular leaf mass because specific leaf weight (leaf dry weight per unit leaf area) is assumed to be constant. $L_{\mathrm{R}}$ ranges between $0-20 \%$ of total leaf area.

Nitrogen and leaf area removal clearly are not mutually exclusive events because consuming nitrogen necessitates reduction of leaf area, and vice versa. However, because of different nitrogen distributions, consumption of a particular amount of leaf area can lead to a wide range of amounts of nitrogen being consumed. Hence, nitrogen and leaf area removal require different accounting procedures and therefore are considered separately, expressed as percentages of total nitrogen and leaf area for convenience in comparing their effects. The model does not require that herbivores be sensitive to the proportion of nitrogen or leaf area that is removed.

Feeding may occur in the top, bottom, or middle of the canopy. Nitrogen and leaf area removal "goals" may each be achieved by following one of four rules (equations are presented in Table 1):

\section{A. Top of Canopy}

1. Nitrogen goal. Foliage with the highest nitrogen content is consumed first, followed by progressive consumption of foliage of lower nitrogen concentration until the nitrogen requirement is fulfilled. More formally, all foliage from depth $0-F$ is removed to satisfy the nitrogen requirement $N_{\mathrm{R}}$ as defined in Table 1, where $N_{\mathrm{L}}$ is the leaf nitrogen per unit area at a particular leaf area depth $F$ from the top of the canopy, and $F_{\mathrm{t}}$ is the total leaf area index.

2. Leaf area goal. Foliage at the top of the canopy is consumed first, and foliage deeper into the canopy is then progressively removed until the leaf area requirement is met. Thus, $L_{\mathrm{R}}$ is the amount of foliage removed from leaf area depth $0-F$ such that it equals $F$, the leaf area index (Table 1).

TABLE 1

Feeding rules that determine the amount and position of foliage that is removed from the canopy. See Appendix A for definitions

\begin{tabular}{|c|c|c|c|}
\hline \multirow{3}{*}{$\begin{array}{l}\text { Goal } \\
\text { Nitrogen }\end{array}$} & \multirow{3}{*}{$\begin{array}{l}\text { Description } \\
\text { Top of canopy } \\
\text { (Rule Al) }\end{array}$} & & \\
\hline & & Formula & \multirow{2}{*}{$\begin{array}{l}\text { Conditions } \\
\left(0 \leqslant F \leqslant F_{1}\right)\end{array}$} \\
\hline & & $N_{\mathrm{R}}=\int_{0} N_{\mathrm{L}} \mathrm{d} F$ & \\
\hline & $\begin{array}{l}\text { Bottom of canopy } \\
\text { (Rule B1) }\end{array}$ & $N_{\mathrm{R}}=\int_{F} N_{\mathrm{L}} \mathrm{d} F$ & $\left(0 \leqslant F \leqslant F_{l}\right)$ \\
\hline & $\begin{array}{l}\text { Middle of nitrogen } \\
\text { distribution } \\
\text { (Rule C1) }\end{array}$ & $N_{\mathrm{R}}=\int_{F_{i}} N_{\mathrm{L}} \mathrm{d} F$ & $0 \cdot 3 N_{\mathrm{t}}=\int_{0} N_{\mathrm{L}} \mathrm{d} F$ \\
\hline & & & $\left(0 \leqslant F_{i} \leqslant F_{j} \leqslant F_{\mathrm{t}}\right)$ \\
\hline & $\begin{array}{l}\text { Middle of leaf area } \\
\text { distribution } \\
\text { (Rule D1) }\end{array}$ & $N_{\mathrm{R}}=\int_{0.3 F_{\mathrm{t}}} N_{\mathrm{L}} \mathrm{d} F$ & $\left(0 \cdot 3 F_{\mathrm{t}} \leqslant F_{j} \leqslant F_{\mathrm{r}}\right)$ \\
\hline \multirow[t]{4}{*}{ Leaf area } & $\begin{array}{l}\text { Top of canopy } \\
\text { (Rule A2) }\end{array}$ & $L_{\mathrm{R}}=F$ & $\left(0 \leqslant F \leqslant F_{1}\right)$ \\
\hline & $\begin{array}{l}\text { Bottom of canopy } \\
\text { (Rule B2) }\end{array}$ & $L_{\mathrm{R}}=F_{\mathrm{1}}-F$ & $\left(0 \leqslant F \leqslant F_{1}\right)$ \\
\hline & $\begin{array}{l}\text { Middle of nitrogen } \\
\text { distribution } \\
\text { (Rule C2) }\end{array}$ & $L_{\mathrm{R}}=F-F_{i}$ & $0 \cdot 3 N_{\mathrm{t}}=\int_{0} N_{\mathrm{L}} \mathrm{d} F$ \\
\hline & $\begin{array}{l}\text { Middle of leaf area } \\
\text { distribution } \\
\text { (Rule D2) }\end{array}$ & $L_{\mathrm{R}}=F-0.3 F_{\mathrm{i}}$ & $\begin{array}{l}\left(F_{i} \leqslant F \leqslant F_{1}\right) \\
\left(0 \cdot 3 F_{\mathrm{t}} \leqslant F \leqslant F_{\mathrm{t}}\right)\end{array}$ \\
\hline
\end{tabular}


Rules A1 and A2 mimic the behavior of herbivores that prefer high nitrogen foliage or feed at the top of a canopy where nitrogen concentration is greatest.

\section{B. Bottom of canopy}

1. Nitrogen goal. Foliage containing the lowest concentration of nitrogen is consumed, with progressive consumption of foliage of higher nitrogen concentration until the nitrogen requirement is fulfilled.

2. Leaf area goal. Starting at the bottom of the canopy, foliage is progressively consumed, working higher up into the canopy until the leaf area requirement is met.

Rules B1 and B2 are appropriate for herbivores that consume foliage from the bottom of a canopy where nitrogen concentration is lowest. Many herbivores, for example vertebrate browsers, are restricted to feeding on the lower branches of trees simply because higher branches are out of reach, but within this restricted range may be sensitive to nutritional quality (Löyttyniemi, 1981).

\section{Middle of nitrogen distribution}

1. Nitrogen goal. Consumption of foliage beginning near the middle of the canopy nitrogen distribution progresses with consumption of foliage that is further from the canopy top until the nitrogen requirement is met. The herbivores are assumed to begin feeding at a depth in the canopy where $30 \%$ of the total nitrogen resides in higher levels.

2. Leaf area goal. Consumption of foliage beginning near the middle of the canopy nitrogen distribution progresses with consumption of foliage deeper into the canopy until the leaf area requirement is satisfied. Herbivores are assumed to start feeding at a depth where $30 \%$ of the total canopy nitrogen resides in higher levels.

Rule $\mathrm{Cl}$ is a compromise between Rules $\mathrm{Al}$ and $\mathrm{B} 1$, whereas Rule $\mathrm{C} 2$ is a compromise between Rules A2 and B2. Feeding towards the middle of a canopy may be preferred to feeding at the top or bottom of a canopy where risks of exposure to predators and harsh environmental conditions may be greater.

\section{Middle of leaf area distribution}

1. Nitrogen goal. Consumption of foliage begins near the middle of the canopy leaf area distribution and progresses deeper into the canopy until the nitrogen requirement is satisfied. This rule is similar to Rule $\mathrm{Cl}$ except that the depth at which feeding begins is fixed at a depth where $30 \%$ of the total leaf area lies in higher levels.
2. Leaf area goal. Consumption of foliage begins near the middle of the leaf area distribution and progresses deeper into the canopy until the leaf area requirement is met. Herbivores are assumed to start feeding at a depth where $30 \%$ of the total leaf area lies in higher levels of the canopy.

In each of the above scenarios, whichever of nitrogen or leaf area removal that is not set to a constant by a feeding rule varies according to the nitrogen distribution with the canopy. It is important to note that the distribution of nitrogen is assumed to be fixed during herbivory, i.e. there is no transport of nitrogen.

\subsection{PENETRATION OF LIGHT THROUGH A CANOPY}

The light intensity (photon flux density or PFD) on the surface of a leaf at leaf area index (LAI) value $F$ from the canopy top is designated as $I_{\mathrm{t}}$, and is an expansion of Beer's law (Monsi \& Saeki, 1953) described by an exponential function of $F$ :

$$
I_{\mathrm{t}}=I_{0} K_{\mathrm{t}} \exp \left(-K_{\mathrm{t}} F\right) /(1-m)
$$

where $I_{0}$ is the PFD on a horizontal plane just above the canopy surface, $K_{\mathrm{t}}$ is the extinction coefficient of light, and $m$ is the leaf transmission coefficient (Saeki, 1960). Irradiance is adjusted for foliage removal by setting light attenuation to zero over regions devoid of leaves.

A squared sine curve (Takenaka, 1986) describes the change over a $24-\mathrm{hr}$ period in PFD above the canopy:

$$
\begin{aligned}
& I_{0}=\hat{I}_{0} \sin ^{2}[\pi(t-6) / 12] \quad(6 \leqslant t<18) \\
& I_{0}=0 \quad(0 \leqslant t<6,18 \leqslant t<24),
\end{aligned}
$$

where $t$ is the solar time (hr) and $\hat{I}_{0}$ is the PFD at noon $(t=12)$.

\subsection{PHOTOSYNTHESIS (CARBON EXCHANGE RATE)}

A non-rectangular hyperbolic function was used to fit the light response curve of photosynthesis (Johnson \& Thornley, 1984; Hirose \& Werger, 1987a, $b$ ):

$$
\ominus P_{\mathrm{g}}^{2}-\left(\phi I_{\mathrm{t}}+P_{\max }\right) P_{\mathrm{g}}+\phi I_{1}+P_{\text {max }}=0,
$$

which expands to

$$
\begin{aligned}
P_{\mathrm{g}}=\left[\phi I_{\mathrm{t}}+P_{\text {max }}-\left\{\left(\phi I_{\mathrm{t}}\right.\right.\right. & \left.+P_{\max }\right)^{2} \\
& \left.\left.-4 \ominus \phi I_{\mathrm{t}} P_{\max }\right\}^{1 / 2}\right] / 2 \ominus,
\end{aligned}
$$

where $P_{\mathrm{g}}$, gross photosynthesis, is net photosynthesis plus dark respiration; $I_{\mathrm{t}}$ is the PFD on the leaf; $P_{\max }$ is the gross photosynthesis at saturating PFD. $\phi$ indicates the initial slope of the curve (quantum yield), and $\Theta$ is a dimensionless parameter that 
TABLE 2

Parameter units and values used in the model. $V$ alues are from Hirose \& Werger $(1987 a, b)$ for Solidago altissima

\begin{tabular}{lcc}
\hline Parameter & Units & Value \\
\hline$m$ & - & 0.086 \\
$K_{1}$ & - & 0.613 \\
$K_{\mathrm{a}}$ & - & 0.798 \\
$F_{\mathrm{l}}$ & $\mathrm{m}^{2} \mathrm{~m}^{-2}$ & $4 \cdot 24$ \\
$N_{\mathrm{l}}$ & $\mathrm{g} \mathrm{m}^{-2}$ & $5 \cdot 62$ \\
$a_{\mathrm{r}}$ & $\mu \mathrm{mol}\left(\mathrm{CO}_{2}\right) \mathrm{m}^{-2} \mathrm{sec}^{-1}$ & $0 \cdot 120$ \\
$b_{\mathrm{r}}$ & $\mu \mathrm{mol}\left(\mathrm{CO}_{2}\right) \mathrm{g}^{-1}(\mathrm{~N}) \mathrm{sec}^{-1}$ & 0.346 \\
$a_{\mathrm{m}}$ & $\mu \mathrm{mol}\left(\mathrm{CO}_{2}\right) \mathrm{m}^{-2} \mathrm{~s}^{-1}$ & -7.86 \\
$b_{\mathrm{m}}$ & $\mu \mathrm{mol}\left(\mathrm{CO}_{2}\right) \mathrm{g}^{-1}(\mathrm{~N}) \mathrm{sec}^{-1}$ & 12.5 \\
$a_{\mathrm{p}}$ & & 0.0211 \\
$b_{\mathrm{p}}$ & $\mathrm{m}^{2} \mathrm{~g}^{-1}(\mathrm{~N})$ & 0.0188 \\
$a_{1}$ & & $1 \cdot 10$ \\
$b_{\mathrm{l}}$ & $\mathrm{m}^{2} \mathrm{~g}^{-1}(\mathrm{~N})$ & -0.251 \\
$\hat{I}_{0}$ & $\mu \mathrm{E} \mathrm{m}^{-2} \mathrm{sec}^{-1}$ & $1000 \cdot 00$ \\
\hline
\end{tabular}

provides the convexity of the curve. Net photosynthesis (the carbon exchange rate) is gross photosynthesis $\left(P_{\mathrm{g}}\right)$ minus dark respiration $(R)$ :

$$
P=P_{\mathrm{g}}-R \text {. }
$$

The light response of net photosynthesis is determined by $N_{\mathrm{L}}$ (the leaf nitrogen concentration per unit area) via linear regressions (Appendix B).

Daily canopy carbon exchange rate $\left(P_{\text {day }}\right.$, daily canopy photosynthesis) is found by integration of leaf photosynthesis at all depths within a canopy over a 24-hr period, and is of the form:

$$
P_{\mathrm{day}}=\int_{0}^{24} \int_{0}^{F_{t}} P(F, t) \mathrm{d} F \mathrm{~d} t .
$$

Following Hirose \& Werger (1987b), parameter values used in equations 1-17 are for Solidago altissima (Table 2). Note that $F_{\mathrm{t}}=4.24$ and $N_{\mathrm{t}}=5.62$ are reference values that were altered when comparing effects of herbivory under different canopy densities.

\section{Results}

\subsection{NO HERBIVORY}

With no herbivory, predictions were identical to those described by Hirose \& Werger $(1987 b)$ and Hirose et al. (1988). Daily canopy photosynthesis at first increased with increasing values of $K_{\mathrm{a}}$ above 0 , but then declined as nitrogen became more concentrated in the top of the canopy (Fig. 1). As canopy density increased but mean nitrogen concentration per unit area remained constant, the $K_{\mathrm{a}}$ that maximized daily canopy photosynthesis increased. The photosynthesis response curve for $N_{t}=5.62$ and $F_{\mathrm{t}}=4 \cdot 24$ (total nitrogen and total leaf area, respect- ively) that is maximal with nitrogen distribution specified by $K_{\mathrm{a}}=1.3$ will be used as a reference throughout the paper.

\subsection{HERBIVORY CAUSING A SHIFT TOWARDS MORE UNIFORM OPTIMAL NITROGEN DISTRIBUTIONS}

If herbivores attack high-nitrogen foliage at the top of a canopy, then a shift in the optimal nitrogen distribution towards a more uniform allocation of nitrogen is predicted. At all nitrogen distributions tested, removal of high-nitrogen foliage reduced total canopy photosynthesis from levels achieved without herbivory. A plant with nitrogen distributed according to a $K_{\mathrm{a}}$ value of 1.3 experienced a $22 \%$ reduction in photosynthesis following removal of $20 \%$ of the canopy nitrogen (Table 3, Rule A1). A plant with nitrogen distributed according to a $K_{\mathrm{a}}$ value of 0.9 experienced only a $13 \%$ reduction in photosynthesis and as a result had the highest daily canopy photosynthesis when $20 \%$ of the canopy nitrogen was removed. Consumption of fixed amounts of high-nitrogen foliage (Rule Al) resulted in a shift of the optimal $K_{\mathrm{a}}$ towards smaller values, indicating that daily canopy photosynthesis was maximized by a more uniform nitrogen distribution than under conditions of no herbivory (Fig. 2). The extent of this shift increased with increasing severity of defoliation.

The optimal $K_{\mathrm{a}}$ was reduced much more severely when a particular percentage of leaf area was removed from the canopy top than when an identical percentage of total nitrogen was removed (Fig. 2). In

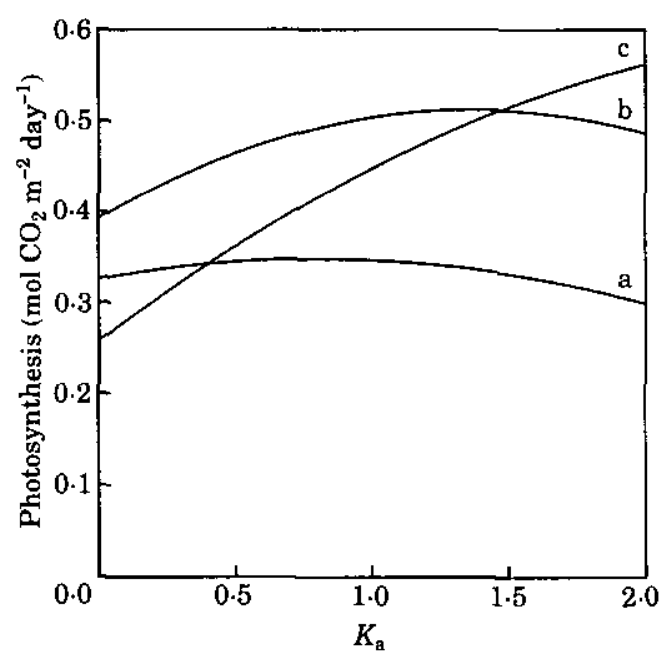

FiG. 1. Daily canopy photosynthesis as a function of nitrogen distribution pattern (coefficient of nitrogen allocation, $K_{\mathrm{a}}$ ) with no herbivory. (a) Total leaf area $F_{\mathrm{t}}=2.1 \mathrm{~m}^{2} \mathrm{~m}^{-2}$, total canopy nitrogen $N_{\mathrm{t}}=2.81 \mathrm{~g} \mathrm{~m}^{-2}$; (b) $F_{\mathrm{t}}=4.24, N_{\mathrm{t}}=5.62$ (used as reference curve); (c) $F_{\mathrm{t}}=8.48, N_{\mathrm{t}}=11 \cdot 24$. 
TABLE 3

Optimal nitrogen distributions $\left(\mathrm{K}_{\text {umax }}\right)$ and changes in net canopy photosynthesis as a function of nitrogen distribution and herbivory. Change in photosynthesis due to herbivore damage is for $20 \%$ leaf area or nitrogen removal, and is expressed as a percentage of photosynthesis achieved with $\mathrm{K}_{a}=1 \cdot 3$ and no herbivory

\begin{tabular}{|c|c|c|c|c|c|}
\hline \multirow{2}{*}{$\begin{array}{l}\text { Herbivore } \\
\text { goal }\end{array}$} & \multirow{2}{*}{$\begin{array}{c}\text { Feeding } \\
\text { rule }\end{array}$} & \multirow{2}{*}{$\begin{array}{c}\text { Location of } \\
\text { damage }\end{array}$} & \multirow[b]{2}{*}{$K_{\mathrm{a} \max }$} & \multicolumn{2}{|c|}{ Change in photosynthesis } \\
\hline & & & & $K_{\mathrm{a}}=1 \cdot 3$ & $K_{\mathrm{a} \max }$ \\
\hline None & - & - & $1 \cdot 3$ & - & - \\
\hline \multirow[t]{4}{*}{ Nitrogen } & Al & Top & 0.9 & $-21 \cdot 8$ & $-12 \cdot 8$ \\
\hline & BI & Bottom & $3 \cdot 1$ & -2.9 & +37.0 \\
\hline & $\mathrm{Cl}$ & Middle & 1.0 & $-9 \cdot 7$ & $-7 \cdot 2$ \\
\hline & D1 & Middle & $1 \cdot 1$ & -11.8 & -9.5 \\
\hline \multirow[t]{4}{*}{ Leaf area } & A2 & Top & 0.5 & $-30 \cdot 6$ & -13.0 \\
\hline & B2 & Bottom & $2 \cdot 1$ & -1.9 & +36.8 \\
\hline & $\mathrm{C} 2$ & Middle & 0.9 & $-[4.3$ & $-9 \cdot 7$ \\
\hline & D2 & Middle & $1 \cdot 1$ & $-10 \cdot 6$ & -8.9 \\
\hline
\end{tabular}

addition, removal of a given percentage of the leaf area from the upper part of the canopy caused a greater reduction in photosynthesis than did removal of the same percentage of total nitrogen, also from the top of the canopy. Whereas removal of $20 \%$ of the total nitrogen by Rule Al resulted in a depression of daily canopy photosynthesis by $22 \%$, removal of $20 \%$ of the total leaf area (Rule A2) reduced daily canopy

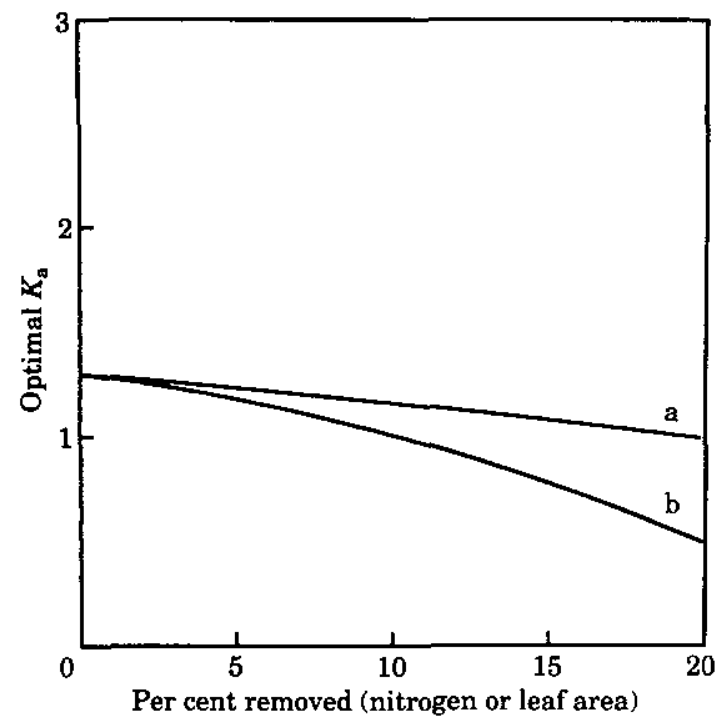

Fig. 2. Optimal nitrogen distribution (expressed as the coefficient of nitrogen allocation, $K_{\mathrm{x}}$ ) as a function of severity of folivory and removal strategy (nitrogen or leaf area) when foliage is removed from the top of a canopy. Total leaf area $F_{1}=4.24$ and total canopy nitrogen $N_{1}=5 \cdot 62$. (a) Rule Al: consumption of foliage with the highest nitrogen concentration first with progressive consumption of foliage of lower nitrogen concentration until the nitrogen requirement $\left(N_{\mathrm{R}}\right)$ is satisfied $\left(0.01 N_{\mathrm{t}} \leqslant N_{\mathrm{R}} \leqslant 0.20 N_{1}\right)$. (b) Rule A2: consumption of foliage at the top of the canopy with progressive consumption of foliage deeper from the top until the leaf area requirement $\left(F_{\mathrm{R}}\right)$ is satisfied $\left(0.01 F_{1} \leqslant F_{\mathrm{R}} \leqslant 0.20 F_{1}\right)$. photosynthesis by $31 \%$ (Table 3 , comparing photosynthesis at $K_{\mathrm{a}}=1 \cdot 3$; Fig. 3 ). Changes in photosynthesis shown in Fig. 3 are broadly representative of the results when the canopy top was damaged by either Rule A1 or A2.

\subsection{HERBIVORY CAUSING AN UPWARD SHIFT IN OPTIMAL NITROGEN DISTRIBUTION}

Consumption of low-nitrogen foliage (Rule B1) at the bottom of the canopy (Rule B2) resulted in an upward shift of the optimal $K_{\mathrm{a}}$, indicating that daily canopy photosynthesis was maximized by greater concentration of nitrogen at the top than under

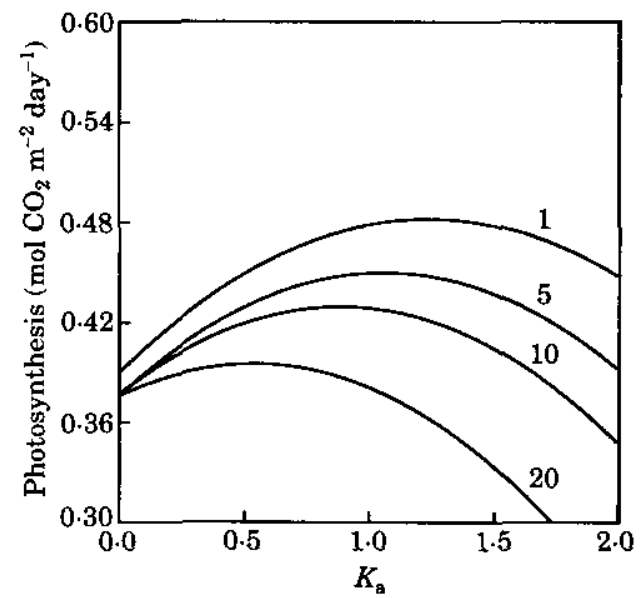

FIG. 3. Daily canopy photosynthesis as a function of nitrogen distribution pattern (coefficient of nitrogen allocation, $K_{\mathrm{a}}$ ) under intensities of herbivory ranging from $1-20 \%$ leaf area removal $\left(0.01 F_{\mathrm{t}} \leqslant F_{\mathrm{R}} \leqslant 0 \cdot 20 F_{1}\right)$. Removal follows Rule A2: consumption of foliage at the top of the canopy with progressive consumption of foliage deeper from the top until the leaf area requirement $\left(F_{\mathrm{R}}\right)$ is satisfied. Total leaf area $F_{1}=4 \cdot 24$ and total canopy nitrogen $N_{1}=5 \cdot 62$. 


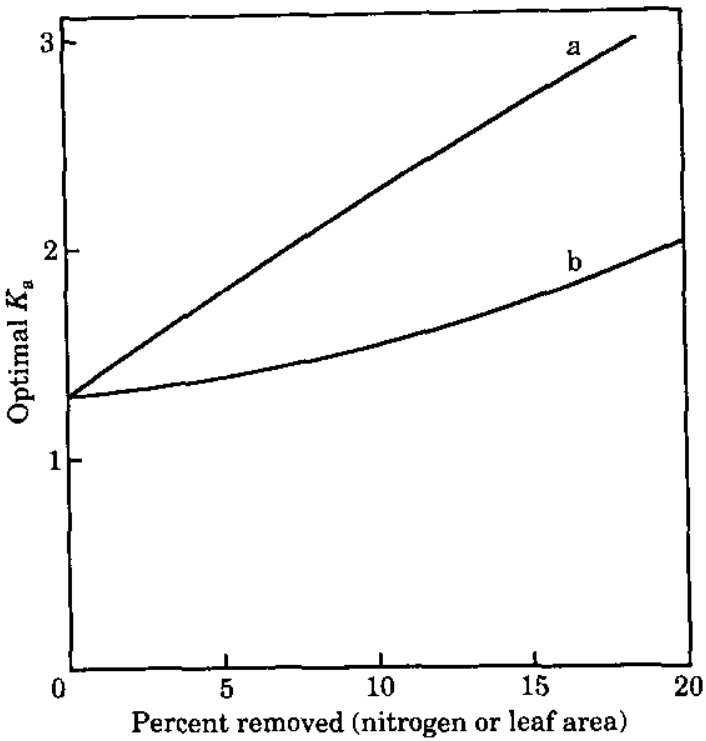

F1G. 4. Optimal nitrogen distribution (expressed as the coefficient of nitrogen allocation, $K_{\mathrm{a}}$ ) as a function of severity of folivory and removal strategy (nitrogen or leaf area) when foliage is removed from the bottom of a canopy. Total leaf area $F_{1}=\mathbf{4} \cdot 24$ and total canopy nitrogen $N_{1}=5.62$. (a) Rule B1: consumption of foliage with the lowest nitrogen concentration first with progressive consumption of foliage of higher nitrogen concentration until the nitrogen requirement $\left(N_{\mathrm{R}}\right)$ is satisfied $\left(0 \cdot 01 N_{\mathrm{t}} \leqslant N_{\mathrm{R}} \leqslant 0 \cdot 20 N_{\mathrm{t}}\right)$. (b) Rule B2: consumption of foliage at the bottom of the canopy with progressive consumption of foliage higher towards the top until the leaf area requirement $\left(F_{\mathrm{R}}\right)$ is satisfied $\left(0 \cdot 01 F_{\mathrm{1}} \leqslant F_{\mathrm{R}} \leqslant 0 \cdot 20 F_{1}\right)$.

conditions of no herbivory (Table 3, Fig. 4). The upward shift resulting from consumption of low-nitrogen foliage was a much stronger response than the downward shift resulting from consumption of highnitrogen foliage, even though identical amounts of nitrogen were consumed. Because the amount of foliage consumed had a relatively small effect on the optimal $K_{\mathrm{a}}$ (see below) when feeding occurred in the bottom of the canopy, differences in the impact of the feeding Rules A1 and B1 resulted from the position of the foliage within the canopy (top vs. bottom) rather than the different amounts of leaf area that were consumed.

In contrast to the greater effect of leaf area removal than nitrogen removal when upper leaves were consumed, the shift in $K_{\mathrm{a}}$ was greater for nitrogen removal than for leaf area removal when lower leaves were removed (Fig. 4). Under Rule B2, photosynthesis peaked at $K_{\mathrm{a}}<2.0$ except for $20 \%$ leaf removal, whereas under Rule B1, photosynthesis peaked at $K_{\mathrm{a}}>2.0$ for nitrogen removal of greater than $5 \%$. This is because nitrogen is unevenly distributed, and it is the nitrogen that is photosynthetically active rather than leaves per se. Removal of a particular percentage of lower leaves removes less nitrogen than does removal of an identical percentage of nitrogen.
For both feeding Rules B1 and B2, the optimal $K_{\mathrm{a}}$ and therefore the optimal nitrogen concentration in the canopy top increased as the severity of herbivory increased (Fig. 5, showing Rule B2 only). At $K_{\mathrm{a}}=1 \cdot 3$, removal of $20 \%$ of the leaf area yielded virtually no change in daily canopy photosynthesis (Table 3), reflecting the smaller photosynthetic value of lower leaves.

The effect of consumption of low-nitrogen foliage on photosynthesis was negligible when $K_{\mathrm{a}}$ was low $\left(K_{\mathrm{a}}<1 \cdot 3\right)$, even under fairly high levels of herbivory. At $K_{\mathrm{a}}=1 \cdot 3$, removal of $20 \%$ of the nitrogen from the bottom of the canopy yielded only a $3 \%$ reduction in photosynthesis (Table 3 ). When $K_{\mathrm{a}}$ was large, however $\left(K_{\mathrm{a}}>1.3\right)$, daily canopy photosynthesis was substantially higher under herbivory than when there was no herbivory (Figs 1 and 5). This seemingly paradoxical result is explained by the relationships among foliar nitrogen, gross photosynthesis, and dark respiration. Below nitrogen concentrations of $0.66 \mathrm{~g} \mathrm{~m}^{-2}$, the carbon exchange rate (net photosynthesis) becomes negative at saturating photon flux density (see $P_{\max }$, Table 2). Hence, leaves with less nitrogen than $0.66 \mathrm{~g} \mathrm{~m}^{-2}$ represent a deficit to canopy photosynthesis at all hours of the day. Removal of these leaves by herbivores therefore removes this carbon drain, yielding an increase in net photosynthesis.

\subsection{HERBIVORY CAUSING MARGINAL CHANGE IN OPTIMAL NITROGEN DISTRIBUTION}

Consumption of foliage from the middle of the canopy had only a slight effect on the optimal $K_{\mathrm{a}}$.

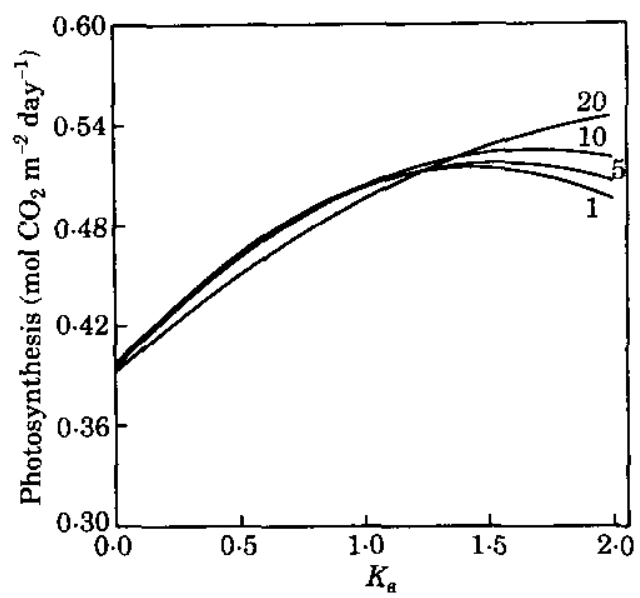

FIG. 5. Daily canopy photosynthesis as a function of nitrogen distribution pattern (coefficient of nitrogen allocation, $K_{\mathrm{a}}$ ) under intensities of herbivory ranging from $1-20 \%$ leaf area removal $\left(0.01 F_{\mathrm{t}} \leqslant F_{\mathrm{R}} \leqslant 0.20 F_{\mathrm{t}}\right)$. Removal follows Rule $\mathrm{B} 2$ : consumption of foliage at the bottom of the canopy with progressive consumption of foliage closer towards the top until the leaf area requirement $\left(F_{\mathrm{R}}\right)$ is satisfied. Total leaf area $F_{\mathrm{I}}=4.24$ and total canopy nitrogen $N_{1}=5 \cdot 62$. 


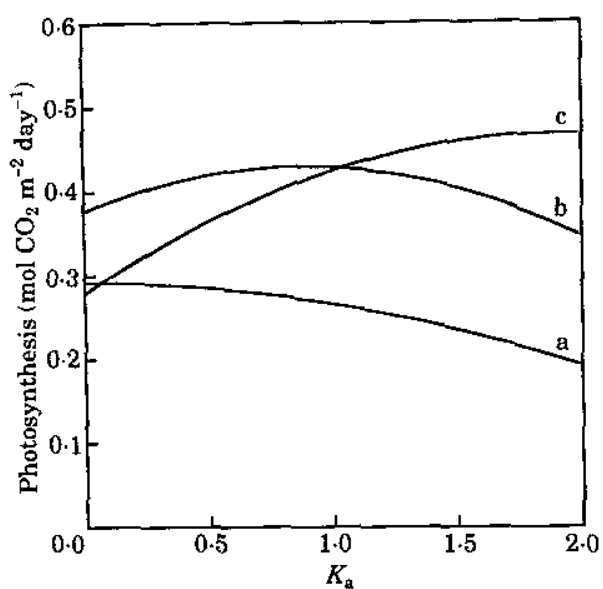

FIG. 6. Daily canopy photosynthesis as a function of nitrogen distribution pattern (coefficient of nitrogen allocation, $K_{\mathrm{a}}$ ) under varying canopy densities and $10 \%$ leaf area removal. Removal follows Rule A2: consumption of foliage at the top of the canopy with progressive consumption of foliage deeper from the top until the leaf area requirement $\left(F_{\mathrm{R}}\right)$ is satisfied. Curve (a) is for $F_{1}=2.1 \mathrm{~m}^{2} \mathrm{~m}^{-2}, N_{\mathrm{t}}=2.81 \mathrm{~g} \mathrm{~m}^{-2}$, curve (b) is for $F_{\mathrm{t}}=4.24, N_{\mathrm{t}}=5.62$, and curve (c) is for $F_{\mathrm{t}}=8.48, N_{\mathrm{t}}=11.24$, representing low, medium and high canopy density, respectively, where $F_{\mathrm{t}}=$ total leaf area index and $N_{\mathrm{t}}=$ total canopy nitrogen.

When herbivores removed a specific amount of nitrogen from the middle of the canopy nitrogen distribution under Rule $\mathrm{Cl}$, there was relatively little change in the optimal $K_{\mathrm{a}}$ under light levels of herbivory. Total canopy photosynthesis also was relatively unchanged under light levels of herbivory ( $1-5 \%$ of canopy nitrogen removed), and even $20 \%$ removal yielded less than a $10 \%$ reduction in the daily canopy photosynthesis when $K_{\mathrm{a}}=1.3$ (Table 3). The difference in the change in photosynthesis for $K_{\mathrm{a}}=1.3$ and $K_{\mathrm{amax}}=1.0$ is slight $(9 \cdot 7 \%$ vs. $7 \cdot 2 \%)$. When herbivores began feeding at a depth in the canopy where $30 \%$ of the total nitrogen was in higher levels, there was a greater reduction in $K_{\mathrm{a}}$ when leaf area removal was the goal than when nitrogen removal was the goal. Daily canopy photosynthesis was reduced by $10 \%$ under Rule C1, and by $14 \%$ under Rule C2 when there was $20 \%$ removal of nitrogen and leaf area, respectively (Table 3).

Effects of herbivory on optimal nitrogen distribution were even less pronounced when nitrogen or leaf area were removed beginning $30 \%$ of the total leaf area from the top of the canopy (Rules DI and $\mathrm{D} 2$, respectively). When $<10 \%$ of the total leaf area was removed, the optimal $K_{\mathrm{a}}$ remained near $1 \cdot 3$. Greater nitrogen or leaf area removal of $20 \%$ reduced the optimal $K_{\mathrm{a}}$ to $1 \cdot 1$, and reduced total canopy photosynthesis by roughly $11 \%$ and $9 \%$ when $K_{\mathrm{a}}=1 \cdot 3$ and $1 \cdot 1$, respectively.

\subsection{EFFECT OF HERBIVORY AT DIFFERENT CANOPY DENSITIES}

Changes in canopy density resulted in virtually identical qualitative shifts in $K_{\mathrm{a}}$ regardless of the feeding rule applied. For example, at all canopy densities tested, removal of $10 \%$ of the leaf area at the top of the canopy caused a reduction in the optimal $K_{\mathrm{a}}$ and total photosynthesis (compare Figs 1 and 6). As canopy density increased, the optimal $K_{\mathrm{a}}$ increased by approximately the same value for all feeding rules, yielding a pattern of curves that is nearly identical for each feeding rule. This indicates that the effects of herbivory are similar in plants with different canopy densities, and that the results of the model are robust to changes in canopy density. In practical terms, this suggests that the results are not limited to plants having the particular canopy structure used in the model, but may be broadly applicable across plant species with different canopy architectures.

\section{Discussion}

Previous models have demonstrated the importance of crown shape and foliage distribution within crowns to plant growth (Jahnke \& Lawrence, 1965; Hatch et al., 1975; Kellomäki et al., 1986; Kramer, 1986; Grace, 1988). Nutrient distributions among foliage appear to be of equal importance. Hirose \& Werger (1987b) demonstrated that the distribution of canopy nitrogen that maximizes daily photosynthesis depends on the total leaf area and total nitrogen in a canopy. Because herbivory reduces both total leaf area and nitrogen in a canopy, the distribution of nitrogen that optimizes canopy photosynthesis with no herbivory may not be the same distribution that optimizes photosynthesis of a canopy damaged by herbivory. The model presented here extends that of Hirose \& Werger (1987b) to include the effects of herbivory on optimal nitrogen distribution within a canopy. The model shows that the optimal distribution of nitrogen is a function of both the position and total surface area of leaves that are removed by herbivores.

The most striking shift in the optimal nitrogen distribution $\left(K_{\mathrm{a}}\right)$ was caused by changes in the position of foliage that was removed. When herbivory occurred in the top of the canopy [either by Rule $\mathrm{Al}$ (nitrogen goal) or A2 (leaf area goal)], subsequent photosynthesis was greater in plants that had placed less nitrogen at the canopy top. Removal of leaves from the bottom of the canopy [Rules B1 (nitrogen goal) and B2 (leaf area goal)] had the opposite effect: photosynthesis following herbivory was greater in plants that had placed more nitrogen at the top of the 
canopy. This suggests that plants that have different patterns of leaf loss to herbivores ideally would have evolved divergent nitrogen distribution strategies in response to expected patterns and consequences of herbivory. One may speculate that plants that are heavily browsed from the top (e.g. annuals, shrubs) should have nitrogen concentrations shifted lower in the canopy. Conversely, plants that are browsed most heavily from the bottom (e.g. tall trees) should place relatively more nitrogen towards the top of the canopy. In addition, because branches may grow out of reach of browsers as a plant grows taller (Bryant et al., 1983), browsed plants may shift greater proportions of nitrogen towards the canopy top as they grow older. Plants experiencing folivory at both the canopy top and bottom would be expected to show a smaller effect of removal because of opposing effects, with the direction of the shift in nitrogen distribution depending on the relative severity of removal at the top and bottom. Insufficient data are available at this time to critically test these predictions,

It is important to note that the shifts in nitrogen distribution described above do not necessarily allow nitrogen or foliage to "escape" herbivory. This point becomes clear when comparing the effects of herbivory at the top of the canopy under different feeding rules. When total leaf removal was regulated by the amount of foliage consumed, identical amounts of foliage were removed regardless of nitrogen distribution, but plants that had their nitrogen distribution shifted away from the top lost less nitrogen. In contrast, when total leaf removal was regulated by the amount of nitrogen consumed, identical amounts of nitrogen were removed regardless of the distribution of nitrogen. However, different amounts of foliage were removed because less high-nitrogen foliage than low-nitrogen foliage was needed by herbivores in order to satisfy the nitrogen requirement. This had the interesting result that the plants that had the highest photosynthetic capacity following herbivory had more foliage removed than plants that concentrated nitrogen more towards the top.

At first analysis, plants that lose more foliage may appear to have suffered greater losses, and hence would have reduced photosynthetic capacity. However, because of the non-uniform nitrogen distribution, foliage loss does not translate directly into loss of photosynthetic capacity. To assess damage accurately, foliage position and nitrogen losses must be accounted for because loss of leaf area alone is probably a poor indicator of herbivore damage (Abrahamson \& Caswell, 1982). Also, because of herbjvore-related changes in canopy architecture and light penetration, photosynthetic losses cannot necessarily be calculated as a simple summation of the photosynthetic capacity of all removed foliage. What is critical to the photosynthesis of a plant following herbivory is not what resources have been removed, but what resources remain. Relative to plants with sub-optimal nitrogen distributions and photosynthetic rates, plants that had the highest photosynthetic rate following herbivory had remaining in their canopies (i) identical amounts of nitrogen distributed among fewer leaves, or (ii) more nitrogen distributed among identical leaf areas. In both cases, nitrogen content per unit area was higher when averaged across the canopy. Apparently, high photosynthetic rate following herbivory was achieved, in part, by maintaining high mean nitrogen concentrations in the foliage. The most successful plants were not those that minimized nitrogen or leaf area losses, but those that balanced these losses with respect to changes in canopy architecture and light penetration.

This has a potentially important implication with regard to plant defense. According to the nutrient stress hypothesis (Bryant et al., 1983; Tuomi et al., 1984), defoliation upsets the carbon/nutrient balance of a plant, and inducible changes in carbon-based allelochemicals are the result of restoring the optimal carbon/nutrient ratio. The critical importance to photosynthesis of nitrogen and its distribution suggests a corollary to this hypothesis: plants should not necessarily protect foliage per se (i.e. minimize loss of leaf area), but should protect the ratio of total nitrogen to leaf area and the distribution of nitrogen within the canopy. Inasmuch as nutrients other than nitrogen may also have optimal distributions, this reasoning applies to these as well. Rather than simply preserving some optimal carbon/nutrient ratio in toto, a plant also may maintain some optimal distribution of nutrients within the canopy. In some plants, increased production and mobilization of secondary plant compounds following herbivory may be a mechanism by which optimal carbon/nutrient ratios and nutrient distributions are restored and maintained.

The adaptive significance of plastic changes in matter partitioning in response to abiotic conditions has been discussed elsewhere (Schlichting, 1986; Bazzaz et al., 1987; Chapin et al., 1987). Such changes are well documented and include decreasing specific leaf weight with increasing shading (Chabot et al., 1979; Fetcher et al., 1983; Jurik, 1986; Oberdauer \& Strain, 1986; Bongers \& Popma, 1988) or with increasing leaf nitrogen concentration (Hirose, 1986, 1987), and increasing root:shoot ratio with decreasing nitrogen availability or increasing light intensity (Chapin, 1980; Hirose, 1986, 1988; Hirose \& Kitajima, 1986; Hunt \& Nicholls, 1986; Hara \& Haraguchi, 1988). 
The potential to maintain an optimal nitrogen distribution in the face of a biotic effect, herbivory, implies a similarly plastic response. Such a strategy would require mobilization and redistribution of canopy nitrogen soon after initiation of herbivore damage. The capacity for rapid response would permit optimal nitrogen distributions to be maintained both before and after herbivory, with only temporary disruption. Although direct evidence does not exist for this supposition, increased production and translocation of mobile forms of nitrogen has been reported (Baldwin, 1988a, $b, 1989$ ), and may play a dual role in plant defense and restoration of optimal nitrogen distributions.

An alternate but not mutually exclusive strategy is for a plant to have a relatively fixed response in which nitrogen is allocated in that distribution that best withstands average levels of folivory. Such plants would have sub-optimal nitrogen distributions except when the average level of folivory is incurred. Accordingly, a significant correlation is predicted between average levels of folivory and nitrogen distribution patterns. As the expected severity of damage increases, plants should take on more highly skewed or more uniform distributions than predicted when herbivory is not taken into consideration. Whether a plant responds in a fixed or plastic manner likely will depend on a variety of factors, including phylogenetic constraints (Givnish, 1987), costs associated with nutrient mobilization and redistribution (Mooney et al., 1983; Chapin et al., 1987), nutrient availability (Bryant et al., 1983; Coley et al., 1985; Hirose, 1988; Werger \& Hirose, 1988) and the expected incidence of folivory over the lifetime of a plant.

Finally, the increase in daily canopy photosynthesis found after removal of low-nitrogen foliage (Rules B1, B2) would appear to raise anew the possibility that herbivory may actually enhance the fitness of a plant. This possibility has been suggested previously for a variety of reasons, but has largely been discounted (see Belsky, 1986). Although this model defines conditions under which herbivory could cause an increase in photosynthesis, several considerations suggest that these conditions would rarely be met, and that herbivory is not likely to enhance plant fitness. First, foliage with low nitrogen concentrations $\left(<0.66 \mathrm{~g} \mathrm{~m}^{-2}\right)$ is probably rare. The observed minimum nitrogen concentration of living Solidago altissima leaves is about $0.90 \pm 0.08 \mathrm{~g} \mathrm{~m}^{-2}$ (mean \pm S.D.), and dead leaves are approximately $0.44 \pm 0.06 \mathrm{~g} \mathrm{~m}^{-2}$ (Hirose \& Werger, 1987b). Presumably, plants will not maintain leaves at very low $\mathrm{N}$ concentrations if they pose a deficit to canopy photosynthesis (Mooney \& Gulmon, 1982). However, all leaves on a plant are likely to pass through this range of nitrogen levels as they senesce. Second, much of the nitrogen in a senescing leaf will be translocated to other parts of the plant, possibly to new foliage at the top of the canopy. Removal of nitrogen by herbivores thus has a lost opportunity cost that is not estimated by the model. Third, optimization of nitrogen distribution is possible not only within a canopy, but within indiridual leaves as well (Evans, 1989). Acclimation to low irradiance may result in a partitioning of nitrogen within a leaf among RuBP carboxylase and thylakoid nitrogen that differs from that of leaves growing under high irradiance. This may alter the balance of gross photosynthesis and dark respiration so that lower leaves have higher (or lower) net photosynthesis and deficit threshold than assumed. Fourth, plant fitness is a function of more than just canopy photosynthesis, although canopy photosynthesis may be a major component. This model focuses exclusively on effects on canopy photosynthesis and does not make direct predictions regarding plant fitness.

I thank G. Belovsky, J. Cresswell, and M. Martin for criticisms on early drafts of the manuscript. Support was provided by McIntire-Stennis grant MICY-00078 and a Rackham Predoctoral Fellowship.

\section{REFERENCES}

Abrahamson, W. G. \& Caswell, H. (1982). On the comparative allocation of biomass, energy, and nutrients in plants. Ecology 63, 982-991.

BALDWIN, I. T. (1988a). The alkaloidal response of wild tobacco to real and simulated herbivory. Oecologia 77, 378-381.

BalDwin, I. T. (1988b). Short term damage-induced increases in tobacco alkaloids protect plants. Oecologia 75, 367-370.

BalDwiN, 1. T. (1989). Mechanism of damage-induced alkaloid production in wild tobacco. J. chem. Ecol. 15, 1661-1679.

Bazzaz, F. A., Chiariello, N. R., Coley, P. D. \& Pitelka, L. F. (1987). Allocating resources to reproduction and defense. BioScience 37, 58-67.

BeLSKY, A. J. (1986). Does herbivory benefit plants? A review of the evidence. Am. Nat. 127, 870-892.

BJöRKMAN, O. (1981). Responses to different quantum flux densities. In: Encyclopedia of Plant Physiology, Vol. 12A (Lange, O. L., Nobel, P. S., Osmond, C. B. \& Ziegler, H., eds) pp. 57-107. Berlin: Springer-Verlag.

BONGERS, F. \& POPMA, J. (1988). Is exposure-related variation in leaf characteristics of tropical rain forest species adaptive? In: Plant Form and Vegetation Structure: Adaptation, Plasticity and Relation to Herbivory (Werger, M. J. A., van der Aart, P. J. M., During, H. K. \& Verhoeven, J. T. A., eds) pp. 19l-200. The Hague: SPB Academic Publishing.

Bryant, J. P., Chapin, F. S. III \& Klein, D. R. (1983). Carbon/ nutrient balance of boreal plants in relation to vertebrate herbivory. Oikos 40, 357-368.

Chabot, B. F. Jurik, T. W. \& Chabot, J. F. (1979). Influence of instantaneous and integrated light flux density on leaf anatomy and photosynthesis. Am. J. Bot. 66, 940-945.

Chapin, F. S. (1980). The mineral nutrition of wild plants. $A$. Rev. ecol. Syst. 11, 233-260. 
Chapin, F. S. IlI, Bloom, A. J., Field, C. B. \& Waring, R. H. (1987). Plant responses to multiple environmental factors. BioScience 37, 4957.

Coley, P. D., Bryant, J. P. \& Chapin, F. S. IlI (1985). Resource availability and plant antiherbivore defense. Science 230, 895-899.

Evans, J. R. (1989). Photosynthesis and nitrogen relationships in leaves of $\mathrm{C}_{3}$ plants. Oecologia 78, 9-19.

Fetcher, N., Strain, B. R. \& Oberbauer, S. F. (1983). The growth, leaf morphology, and water relations of seedlings of two species of topical tress. Oecologia 58, 314-319.

FIELD, C. (1983). Allocating leaf nitrogen for the maximization of carbon gain: leaf age as a control on the allocation program. Oecologia 56, 341.347.

Field, C. \& Mooney, H. A. (1986). The photosynthesis-nitrogen relationship in wild plants. In: On the Economy of Form and Function (Givnish, T. J., ed.) pp. 25-55. Cambridge: Cambridge University Press.

Givnish, T. J. (1987). Comparative studies of leaf form: assessing the relative roles of selective pressures and phylogenetic constraints. New' Phytol. 106, 131-160.

GRACE, J.C. (1988). Effect of foliage distribution within tree crowns on intercepted radiant energy and photosynthesis. In: Plant Form and Vegetation Structure: Adaptation, Plasticity and Relation to Herbitory (Werger, N. J. A., van der Aart, P. J. M., During, H. J. \& Verhoeven, J. T. A., eds) pp. 153-159. The Hague: SPB Academic Publishing.

Gulmon. S. L. \& CHU, C. C. (1981). The effects of light and nitrogen on photosynthesis, leaf characteristics, and dry matter allocation in the chaparral shrub, Diplacus aurantiacus. Oecologia 49, 207.212.

Hara, T. \& Haraguchi, A. (1988). Phenotypic responses of plants to environmental conditions. In: Plant Form and Vegetation Structure: Adaptation, Plasticity and Relation to Herbivory (Werger, M. J. A., van der Aart, P. J. M., During, H. J. \& Verhoeven, J. T. A., eds) pp. 147-151. The Hague: SPB Academic Publishing.

Hatch, C. R.. Gerrard, D. J. \& Tappeiner, J. C. II (1975), Exposed crown surface area: a mathematical index of individual tree growth potential. Can. J. For. Res. 5, 224-228.

HiROSE, T. (1986). Nitrogen uptake and plant growth. II. An empirical model of vegetative growth and partitioning. Ann. Bot. 58, 487496.

HiRose, T. (1987). A vegetative plant growth model: adaptive significance of phenotypic plasticity in matter partitioning. Funct, Ecol. 1, 195-202.

Hirose, T. (1988). Nitrogen availability, optimal shoot/root ratios and plant growth. In: Plant Form and Vegetation Structure: Adaptation, Plasticity and Relation to Herbivory (Werger, M. J. A., van der Aart, P. J. M., During, H. J. \& Verhoeven, J. T. A., eds) pp. 135-145. The Hague: SPB Academic Publishing.

Hirose, T. \& Kitajima, K. (1986). Nitrogen uptake and plant growth. I. Effect of nitrogen removal on growth of Polygonum cuspidatum. Ann. Bot. 58, 479-486.

Hirose, T. \& Werger, M. J. A. (1987a). Nitrogen use efficiency in instantaneous and daily photosynthesis of leaves in the canopy of a Solidago altissima stand. Physiol. Pl. 70, 215-222.

Hirose, T., Werger, M. J. A. (1987b). Maximizing daily canopy photosynthesis with respect to the leaf nitrogen allocation pattern in the canopy. Oecologia 75, 520-526.

Hirose, T., Werger, M. J. A., Pons, T. L. \& Van Rheenan, J. W. A. (1988). Canopy structure and leaf nitrogen distribution in a stand of Lysimachia culgaris $\mathrm{L}$. as influenced by stand density. Oecologia $77,145150$.

HunT, R. \& Nicholls, A. O. (1986). Stress and the course control of growth and root-shoot partitioning in herbaceous plants. Oikos 47, $149 \cdots 158$.
JAHNKE, L. S. \& LAWRENCE, D. B. (1985). Influence of photosynthetic crown structure on potential productivity of vegetation, based primarily on mathematical models. Ecology 46, 319-326.

JoHNSON, I. R. \& Thornley, J. H. M. (1984). A model of instantaneous and daily canopy photosynthesis. J. theor. Biol. 107, $531-545$.

JURIK, T. W. (1986). Temporal and spatial patterns of specific leaf weight in successional northern hardwood tree species. Am. J. Bot. 73, 1083-1092.

KellomäKI, S., KuUluvainen, T. \& Kurttio, O. (1986). Effect of crown shape, crown structure, and stand density on the light absorption in a tree stand. In: Crown and Canopy Structure in Relation to Productivity (Fujimori, T. \& Whitehead, D. eds). Ibaraki, Japan: Forestry and Forest Products Research Institute.

KRAMER, H. (1986). Relation between crown parameters and volume increment of Picea abies stands damaged by environmental pollution. Scand. J. For. Res. 1, 25l-263.

LÖYTTYNIEMI, K. (1981). Nitrogen fertilization and nutrient contents in Scots pine in relation to the browsing preference by moose (Alces alces). Folia Forestalia 487, 1-14.

MATTSON, W. J. (1980). Herbivory in relation to plant nitrogen content. A. Rer. Ecol. Syst. 11, 119-161.

MONS1, M., SAEK1, T. (1953). Uber den Lichtfaktor in den Pflanzengesellschaften und seine Bedeutung für die Stoffproduction. Jap. J. Bot. 14, 22-52.

MoOney, H. A., Field, C., Gulmon, S. L. \& Bazzaz, F. A. (1981). Photosynthetic capacity in relation to leaf position in desert versus old field annuals. Oecologia 50, 109-112.

MOONEY, H. A. \& Gulmon, S. L. (1982). Constraints on leaf structure and function in reference to herbivory. BioScience 32 , 198-206.

MoOney, H. A., Gllmon, S. L. \& Johnson, N. D. (1983). Physiological constraints on plant chemical defenses. In: Plant Resistance to Insects (Hedin, P. A., ed.) ACS Symposium No. 208, pp. 21*36. Washington, DC: DCACS Publishing.

Oberdauer, S. F. \& Strain, B. R. (1986). Effects of canopy position and irradiance on the leaf physiology and morphology of Pentaclethra macroloha (Mimosaceae). Am. J. Bot. 73, 409-416.

SAEKI, T. (1960). Interrelationships between leaf amount, light distribution and total photosynthesis in a plant community. Bot. Mag. Tokyo 73, 55-63.

Schlichting, C. D. (1986). The evolution of phenotypic plasticity in plants. A. Rev. Ecol. Syst. 17, 667-693.

SCRIBER, J. M. (1984). Host plant suitability. In: Chemical Ecology of Insects (Bell, W. J. \& Carde, R. T., eds) pp. 159-202. London: Chapman and Hall.

TAKENAKA, A. (1986). Studies on the forest light environment and the ecological significance of light-response characteristics of leaf photosynthesis. Ph.D. Thesis, University of Tokyo.

Tuomi, J., Niemelä, P., Haukioja, E., Siren, S. \& Neuvonen, S. (1984). Nutrient stress: an explanation for plant anti-herbivore responses to defoliation. Oecologia 61, 208-210.

Werger, M. J. A. \& Hirose, T. (1988). Effects of light climate and nitrogen partitioning on the canopy structure of stands of a dicotyledonous, herbaceous vegetation. In: Plant Form and Vegetation Structure: Adaptation, Plasticity and Relation to Herbivory (Werger, M. J. A., van der Aart, P. J. M., During, H. J. \& Verhoeven, J. T. A., eds) pp. 171-181. The Hague: SPB Academic Publishing.

WHITE, T. C. R. (1978). The importance of a relative shortage of food in animal ecology. Oecologia 33, 71-86.

WIEGERT, R. G. \& OWEN, D. F. (1971). Trophic structure, available resources and population density in terrestrial vs. aquatic ecosystems. J. theor. Biol. 30, 69-81. 


\section{APPENDIX A}

\section{Symbol Definitions}

$N_{\mathrm{L}} \quad$ Nitrogen concentration per unit leaf area; $\mathrm{g} \mathrm{m}^{-2}$

$N_{0} \quad N_{\mathrm{L}}$ at the top layer of the canopy; $\mathrm{g} \mathrm{m}^{-2}$

$K_{\mathrm{a}} \quad$ Coefficient of nitrogen allocation; dimensionless

$F \quad$ Leaf area index from the canopy top; $\mathrm{m}^{2} \mathrm{~m}^{-2}$

$F_{\mathrm{t}} \quad$ Total leaf area per unit ground area; $\mathrm{m}^{2} \mathrm{~m}^{-2}$

$N_{\mathrm{t}} \quad$ Total leaf nitrogen per unit ground area; $\mathrm{g} \mathrm{m}^{-2}$

$N_{\mathrm{R}} \quad$ Nitrogen removed by herbivores; $\mathrm{g} \mathrm{m}^{-2}$

$L_{\mathrm{R}} \quad$ Leaf area removed by herbivores; $\mathrm{m}^{2} \mathrm{~m}^{-2}$

$I_{1} \quad$ Irradiance on a leaf surface; $\mu \mathrm{E} \mathrm{m}^{-2} \mathrm{sec}^{-1}$

$I_{0} \quad$ Irradiance on a horizontal plane above the canopy; $\mu \mathrm{E} \mathrm{m}^{-2} \mathrm{sec}^{-1}$

$\hat{I} \quad \mathrm{I}_{0}$ at $1200 \mathrm{hr} ; \mu \mathrm{E} \mathrm{m}^{-2} \mathrm{sec}^{-1}$

$K_{\mathrm{t}} \quad$ Coefficient of light extinction; dimensionless

$m$ Transmission coefficient of light; dimensionless

$t \quad$ Solar time; hr

$P \quad$ Net photosynthesis (instantaneous $\mathrm{CO}_{2}$ exchange rate of an individual leaf; $\mu \mathrm{mol}\left(\mathrm{CO}_{2}\right) \mathrm{m}^{-2} \mathrm{sec}^{-1}$

$P_{\text {day }} \quad$ Daily canopy (net) photosynthesis $\left(\mathrm{CO}_{2}\right.$ exchange rate); mol $\left(\mathrm{CO}_{2}\right) \mathrm{m}^{-2}$ day ${ }^{-1}$

$P_{\mathrm{g}} \quad$ Gross photosynthesis ( $P$ plus dark respiration) of an individual leaf; $\mu$ mol $\left(\mathrm{CO}_{2}\right) \mathrm{m}^{-2} \mathrm{sec}^{-1}$

$P_{\max } \quad$ Gross photosynthesis at light saturation; $\mu \mathrm{mol}\left(\mathrm{CO}_{2}\right) \mathrm{m}^{-2} \mathrm{sec}^{-1}$

$R \quad$ Dark respiration; $\mu \mathrm{mol}\left(\mathrm{CO}_{2}\right) \mathrm{m}^{-2} \mathrm{sec}^{-1}$

$a_{\mathrm{m}} \quad Y$ intercept in the regression of $P_{\max }$ vs. $N_{\mathrm{L}} ; \mu \mathrm{mol}\left(\mathrm{CO}_{2}\right) \mathrm{m}^{-2} \mathrm{sec}^{-1}$

$a_{\mathrm{p}} \quad Y$ intercept in the regression of $\phi$ vs. $N_{\mathrm{L}} ; \mu \mathrm{mol}\left(\mathrm{CO}_{2}\right) \mu \mathrm{E}^{-1}$

$a_{\mathrm{r}} \quad Y$ intercept in the regression of $R$ vs. $N_{\mathrm{L}} ; \mu \mathrm{mol}\left(\mathrm{CO}_{2}\right) \mathrm{m}^{-2} \mathrm{sec}^{-1}$

$a_{\mathrm{t}} \quad Y$ intercept in the regression of $\Theta$ vs. $N_{\mathrm{L}}$; dimensionless

$b_{\mathrm{m}} \quad$ Slope in the regression of $P_{\max }$ vs. $N_{\mathrm{L}} ; \mu \mathrm{mol}\left(\mathrm{CO}_{2}\right) \mathrm{m}^{-2} \mathrm{sec}^{-1}$

$b_{\mathrm{p}} \quad$ Slope in the regression of $\phi$ vs. $N_{\mathrm{L}} ; \mathrm{m}^{-2} \mathrm{~g}^{-1}(\mathrm{~N})$

$b_{\mathrm{r}} \quad$ Slope in the regression of $R$ vs. $N_{\mathrm{L}}$;

$b_{\mathrm{t}} \quad$ Slope in the regression of $\Theta$ vs. $N_{\mathrm{L}} ; \mu \mathrm{mol}(\mathrm{C})_{2} \mathrm{~g}^{-1}(\mathrm{~N}) \mathrm{sec}^{-1}$

$\phi \quad$ Quantum yield (initial slope of a light response curve of photosynthesis); $\mu \mathrm{mol}\left(\mathrm{CO}_{2}\right) \mu \mathrm{E}^{-1}$

$\Theta \quad$ Convexity of a light response curve of photosynthesis; dimensionless

\section{APPENDIX B}

The light response of net photosynthesis is described by regressions with $N_{\mathrm{L}}$ as

$$
\begin{aligned}
R & =a_{\mathrm{r}}+\mathrm{b}_{\mathrm{r}} N_{\mathrm{L}} \\
P_{\max } & =a_{\mathrm{m}}+b_{\mathrm{m}} N_{\mathrm{L}} \\
\phi & =a_{\mathrm{p}}+b_{\mathrm{p}} N_{\mathrm{L}} \\
\Theta & =a_{\mathrm{t}}+b_{\mathrm{i}} N_{\mathrm{L}},
\end{aligned}
$$

where $a_{i}$ and $b_{i}$ are regression coefficients. 